\title{
The Fusarium metabolite culmorin suppresses the in vitro glucuronidation of deoxynivalenol
}

\author{
Lydia Woelflingseder ${ }^{1} \cdot$ Benedikt Warth ${ }^{1} \cdot$ Immina Vierheilig $^{1} \cdot$ Heidi Schwartz-Zimmermann ${ }^{2} \cdot$ Christian Hametner $^{3}$. \\ Veronika Nagl $^{4} \cdot$ Barbara Novak $^{4} \cdot$ Bojan Šarkanj $^{5} \cdot$ Franz Berthiller $^{2} \cdot$ Gerhard Adam $^{6} \cdot$ Doris Marko $^{1}$ (1)
}

Received: 18 February 2019 / Accepted: 18 April 2019 / Published online: 2 May 2019

(C) The Author(s) 2019

\begin{abstract}
Glucuronidation is a major phase II conjugation pathway in mammals, playing an important role in the detoxification and biotransformation of xenobiotics including mycotoxins such as deoxynivalenol (DON). Culmorin (CUL), a potentially cooccurring Fusarium metabolite, was recently found to inhibit the corresponding detoxification reaction in plants, namely DON-glucoside formation, raising the question whether CUL might affect also the mammalian counterpart. Using cell-free conditions, CUL when present equimolar $(67 \mu \mathrm{M})$ or in fivefold excess, suppressed DON glucuronidation by human liver microsomes, reducing the formation of DON-15-glucuronide by 15 and 50\%, and DON-3-glucuronide by 30 and $50 \%$, respectively. Substantial inhibitory effects on DON glucuronidation up to $100 \%$ were found using the human recombinant uridine 5'-diphospho-glucuronosyltransferases (UGT) 2B4 and 2B7, applying a tenfold excess of CUL (100 $\mu \mathrm{M}$ ). In addition, we observed the formation of a novel metabolite of CUL, CUL-11-glucuronide, identified for the first time in vitro as well as in vivo in piglet and human urine samples. Despite the observed potency of CUL to inhibit glucuronidation, no significant synergistic toxicity on cell viability was observed in combinations of CUL $(0.1-100 \mu \mathrm{M})$ and DON $(0.01-10 \mu \mathrm{M})$ in HT-29 and HepG2 cells, presumably reflecting the limited capacity of the tested cell lines for DON glucuronidation. However, in humans, glucuronidation is known to represent the main detoxification pathway for DON. The present results, including the identification of CUL-11-glucuronide in urine samples of piglets and humans, underline the necessity of further studies on the relevance of CUL as a potentially co-occurring modulator of DON toxicokinetics in vivo.
\end{abstract}

Keywords Natural contaminants $\cdot$ Drug metabolism $\cdot$ Fungal metabolites $\cdot$ Chemical mixtures $\cdot$ Drug-exposome interactions

\begin{tabular}{|c|c|c|c|}
\hline Abbreviations & & DON & Deoxynivalenol \\
\hline $\mathrm{ACN}$ & Acetonitrile & DON-3-GlcA & Deoxynivalenol-3-glucuronide \\
\hline ACTB1 & B-Actin & DON-7-GlcA & Deoxynivalenol-7-glucuronide \\
\hline a.u. & Arbitrary unit & DON-15-GlcA & Deoxynivalenol-15-glucuronide \\
\hline cDNA & Complementary deoxyribonucleic acid & EFSA & European food safety authority \\
\hline $\mathrm{CE}$ & Collision energy & $\mathrm{EV}$ & Expected value \\
\hline CUL & Culmorin & GAPDH & Glyceraldehyde-3-phosphate \\
\hline CUL-11-GlcA & Culmorin-11-glucuronide & & dehydrogenase \\
\hline CUL-GlcA & Culmorin-glucuronide & LOD & Limit of detection \\
\hline DP & Declustering potential & $\mathrm{MeOH}$ & Methanol \\
\hline DMSO & Dimethyl sulfoxide & mRNA & Messenger ribonucleic acid \\
\hline & & n. a. & Not assessed \\
\hline Electronic supplem & entary material The online version of this & PEG 300 & Polyethylene glycol 300 \\
\hline article (https://doi. & $\mathrm{rg} / 10.1007 / \mathrm{s} 00204-019-02459-\mathrm{w})$ contains & qPCR & Quantitative polymerase chain reaction \\
\hline supplementary mat & rial, which is available to authorized users. & RNA & Ribonucleic acid \\
\hline $\begin{array}{l}\text { Doris Marko } \\
\text { doris.marko@ }\end{array}$ & vie.ac.at & RSD & Relative standard deviation \\
\hline
\end{tabular}




$\begin{array}{ll}\text { UDPGA } & \text { Uridine diphosphate glucuronic acid } \\ \text { UGT } & \text { Uridine } \\ & \text { 5'-diphospho-glucuronosyltransferase }\end{array}$

\section{Introduction}

Mycotoxins are toxic compounds formed as secondary metabolites by different fungal genera such as Fusarium, Aspergillus, Penicillium and Alternaria. As toxigenic molds frequently contaminate agricultural crops pre- or post-harvest, mycotoxins may enter the food and feed chains, posing a potential risk to both human and animal health. Recent multi-mycotoxin surveys as well as human biomonitoring studies point at co-occurrence of various mycotoxins (Kovalsky et al. 2016; Marin et al. 2018; Warth et al. 2013b). It is rather the rule than the exception to be exposed simultaneously to a mixture of several mycotoxins through the diet. Nonetheless, mycotoxin risk assessment is still predominantly based on single-compound toxicity studies (EFSA et al. 2018, 2017a, b), and combinatory interactions, in particular with co-occurring fungal metabolites considered themselves to be of low toxicological relevance, are yet rarely taken into account.

Glucuronidation is a major phase II conjugation pathway for xenobiotics in most mammalian species. Glucuronide-conjugation of mycotoxins, including deoxynivalenol (DON), has been investigated in several studies (Maul et al. 2012; Schwartz-Zimmermann et al. 2017). Uridine 5'-diphospho-glucuronosyltransferases (UDP-glucuronosyltransferases, UGTs), integral membrane proteins localized in the endoplasmic reticulum, catalyze this transfer of glucuronic acid to the substrate (Dong et al. 2012). In humans, 22 UGT isoforms exist, which were classified into four gene families: UGT 1, UGT 2, UGT 3 and UGT 8 (Rowland et al. 2013). Regarding UGT tissue localization, numerous studies reported that in humans, the liver shows the highest abundance of UGT enzymes (Court et al. 2012; Izukawa et al. 2009; Ohno and Nakajin 2009), while extra-hepatic drug metabolism is considered to occur predominantly in kidneys and the gastrointestinal tract (Tourancheau et al. 2018; Tukey and Strassburg 2000).

DON (Fig. 1a), a type-B trichothecene, is one of the most abundant Fusarium mycotoxins in temperate climate regions (EFSA et al. 2017b; Kovalsky et al. 2016; Streit et al. 2013). Due to its strong emetic effect, it is also referred to as vomitoxin. The $\mathrm{C} 12-\mathrm{C} 13$ epoxide moiety was shown to be crucial for its main mechanism of action, the interaction with the ribosomal 60S subunit, resulting in the inhibition of protein bio-synthesis (Garreau de Loubresse et al. 2014; Ueno 1977) and the induction of ribotoxic stress (Iordanov et al. 1997; Laskin et al. 2002; Pestka et al. 2004). Further mechanisms associated with DON exposure comprise, among others, proinflammatory processes (Pestka 2008, 2010a) and the activation of autophagic reactions (Del Favero et al. 2018). In several human biomonitoring studies, between 66 and $91 \%$ of ingested DON was excreted into urine as two different glucuronide conjugates: DON-3-glucuronide (DON-3-GlcA) and DON-15-glucuronide (DON-15-GlcA), the latter identified as the dominating isomer in humans (EFSA et al. 2017b; Vidal et al. 2018; Warth et al. 2013a). Maul et al. (2015) tested twelve commercially available human recombinant UGTs, whereof two isoforms led to the formation of the DON-glucuronides. UGT 2B4 predominantly formed DON15-GlcA, whereas UGT 2B7 mainly catalyzed the formation of DON-3-GlcA.

The sesquiterpene diol culmorin (CUL, Fig. 1b), firstly isolated by Ashley et al. (1937), is another secondary metabolite produced by various Fusarium species, such as F. culmorum, $F$. graminearum, F. venenatum and $F$. cerealis (syn. crookwellense) (Greenhalgh et al. 1984; Lauren et al. 1987; Miller and MacKenzie 2000; Pedersen and Miller 1999). Occurrence levels of this fungal metabolite typically correlate with DON contamination levels, resulting in CUL concentrations about 2-3 times higher than those found for DON (Ghebremeskel and Langseth 2001; Uhlig et al. 2013). CUL was detected in $63 \%$ of 82 analyzed feed samples sourced in Europe, America and Australia at median and maximum concentrations of 195 and 44,616 $\mu \mathrm{g} / \mathrm{kg}$, respectively (Streit et al. 2013). Further studies identified CUL in $95-100 \%$ of Norwegian barley, oats and wheat samples, reaching median and maximum levels of
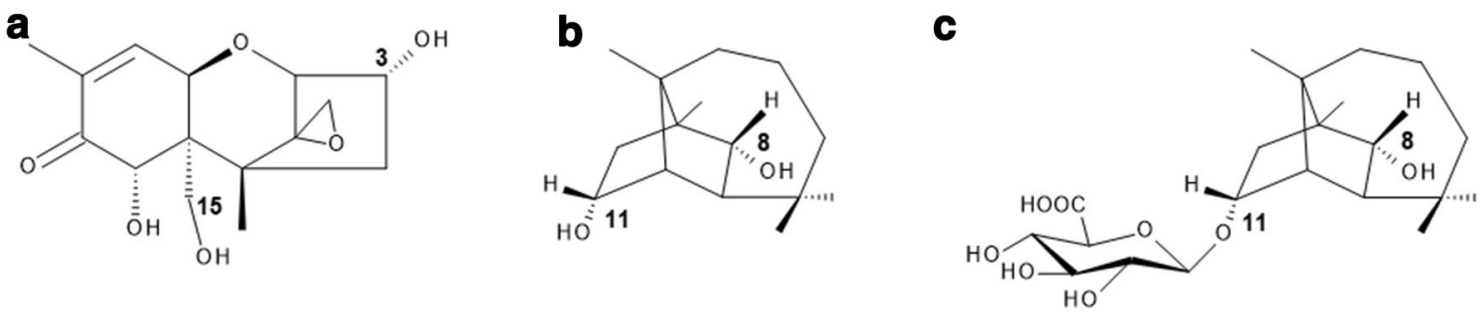

Fig. 1 Chemical structures of the investigated Fusarium secondary metabolites and the newly identified glucuronidated CUL metabolite: (a) deoxynivalenol (DON), (b) culmorin (CUL), and (c) CUL-11-glucuronide (CUL-11-GlcA). Positions for potential glucuronidation are indicated 
2000 and 31,500 $\mu \mathrm{g} / \mathrm{kg}$, respectively (Uhlig et al. 2013). CUL is often referred to as 'fungal secondary metabolite'. However, it might also be considered as an 'emerging mycotoxin', defined by Vaclavikova et al. (2013) as mycotoxins which are 'neither routinely determined, nor legislatively regulated; however, the evidence of their incidence is rapidly increasing'. Information on the toxicological relevance of CUL is limited. In the Ames test, mutagenic effects could be excluded (Pedersen and Miller 1999). CUL was shown to mediate weak antifungal activity (Strongman et al. 1987) and to be phytotoxic to wheat coleoptile tissue at concentrations between 0.1 and $1 \mu \mathrm{M}$ (Wang and Miller 1988). Administration of CUL-contaminated feed to caterpillars and swine for 7 days $(25 \mathrm{mg} / \mathrm{kg})$ and 21 days $(2 \mathrm{mg} / \mathrm{kg})$ did not affect negatively the weight and performance of the animals (Dowd et al. 1989; Rotter et al. 1992). Nevertheless, in the same studies, potential combinatory interactions of CUL ( $10 \mathrm{mg} / \mathrm{kg}$ diet) with DON ( $25 \mathrm{mg} / \mathrm{kg}$ diet) were reported, leading to a significant weight reduction and an increased mortality of Helio zea larvae, in comparison to the effects caused by DON alone (Dowd et al. 1989). In pigs such interactions of CUL and DON could not be confirmed (Rotter et al. 1992). However, recently Michlmayr et al. (unpublished) identified CUL as an inhibitor of the UDP-glucosyltransferase Os79, resulting in a decreased DON-3-glucoside formation. Whereas mammalian enzymes use UDP-glucuronic acid as a substrate for conjugation reactions, the equivalent in plants is UDP-glucose, catalyzing, e.g., the transfer to the hydroxyl group at the $\mathrm{C}-3$ position of DON (Poppenberger et al. 2003).

Based on the recent finding by Michlmayr et al. (unpublished) in planta, we aimed to address the question whether co-occurrence and presence of CUL affects also the major DON-detoxifying pathway in humans, namely glucuronidation. Therefore, we performed glucuronidation assays, using commercially available rat and human liver microscomes, as well as UGT Supersomes ${ }^{\mathrm{TM}}$. In these experiments, a new glucuronide metabolite of CUL could be identified, CUL-11-glucuronide (CUL-11-GlcA, Fig. 1c). Furthermore, the presence of CUL-11-GlcA was confirmed in urine samples of CUL-fed pigs and in a human urine sample. In addition, we determined the transcription levels of the UGTs relevant for DON glucuronidation (UGT 2B4, UGT 2B7) in human cell lines originating from intestine (HT-29, Caco-2) and liver (HepG2), and investigated whether inhibitory effects of co-occurring CUL might result in synergistic toxicity of DON and CUL.

\section{Materials and methods}

\section{Chemicals and reagents}

CUL was produced and purified as described in Weber et al. (2018). CUL-11-GlcA was produced from rat liver microsomes according to a similar protocol as used by Schwartz-Zimmermann et al. (2017). In total, $1.5-\mathrm{mg}$ CUL was treated with pooled liver microsomes from male Sprague-Dawley rats (BioIVT, Brussels, Belgium), yielding one main substance with a glucuronidation yield of $>95 \%$. The product was isolated by preparative HPLC and consecutive NMR measurements revealed the compound to be CUL-11-GlcA. Details on NMR analysis and structure confirmation are presented in the Online Resource (Figs. S1, S2 and Table S1). DON was purchased from Romer Labs (Tulln, Austria). CUL was dissolved in dimethyl sulfoxide (DMSO) at $50 \mathrm{mM}$ and DON in water (LC-MS grade) to obtain a stock solution of $10 \mathrm{mM}$. Recombinant human UGT 2B4 and UGT 2B7 were purchased from Corning Life Sciences (Amsterdam, Netherlands). Human liver microsomes (pooled from 25 donors of mixed gender, $20 \mathrm{mg} / \mathrm{mL}$ ) were purchased from BioIVT (Brussels, Belgium). Alamethicin, magnesium chloride, uridine-diphosphoglucuronic acid (UDPGA) and uridine-diphospho- $N$-acetylglucosamine were obtained from Sigma Aldrich (Vienna, Austria). For mass spectrometric measurements, methanol $(\mathrm{MeOH})$, acetonitrile (ACN), acetic acid and water of LC-MS grade were purchased from Sigma (Fluka; Vienna, Austria). A multi-component standard including DON and its metabolites (DON3-sulfate, DON-15-sulfate, DON-3-GlcA and DOM-1) was prepared according to Warth et al. (2016). In addition, a second standard mix containing CUL and CUL-11-GlcA was prepared. For the animal experiment, polyethylene glycol 300 (PEG 300, Merck, Germany) was mixed with purified water $(50 / 50, v / v)$. Thereafter, appropriate amounts of CUL were dissolved in 50\% PEG 300 to obtain a stock solution of $300 \mu \mathrm{g} / \mathrm{mL}$.

\section{Glucuronidation assay}

The potential inhibitory effect of CUL on DON glucuronidation was analyzed using liver microsomes from rats or humans. In principle, the assays were performed as described previously for DON alone (Schwartz-Zimmermann et al. 2017). Three groups were set up: (1) DON (as positive control, $n=5)$, (2) CUL/DON (1:1 molar ratio, $n=5$ ), (3) CUL/DON (1:5 molar ratio, $n=5$ ). The concentration of DON in all cases was $20 \mathrm{mg} / \mathrm{L}(67 \mu \mathrm{M})$, while the molar excess of the co-substrate UDPGA was at least 20 -fold. After stopping the reactions, samples were diluted $1: 10$ with $20 \%$ aqueous methanol and the formed glucuronides were determined by LC-MS/MS.

Furthermore, the effect of CUL on the glucuronidation of DON was tested using two different UGT isoforms (UGT 2B4, UGT 2B7) according to Maul et al. (2015). Human UGT Supersomes ${ }^{\mathrm{TM}}$ were used at a concentration of $1 \mathrm{mg} /$ $\mathrm{mL}$. Mixtures of the recombinant UGT isoform containing $100 \mathrm{mM}$ potassium phosphate buffer ( $\mathrm{pH} 7.4$ ), $5 \mathrm{mM}$ 
$\mathrm{MgCl}_{2}$ and $25 \mu \mathrm{g} / \mathrm{mL}$ alamethicin were placed on ice for $15 \mathrm{~min}$ to allow alamethicin pore formation. $100 \mu \mathrm{M} \mathrm{CUL}$ or the respective solvent control was added to the incubation solution and pre-incubated at $37^{\circ} \mathrm{C}$ for $30 \mathrm{~min}$. Afterwards, DON $(10 \mu \mathrm{M})$ or CUL $(100 \mu \mathrm{M})$ was added and the reaction was initiated by the addition of UDPGA $(2.5 \mathrm{mM})$. After further incubation for $1 \mathrm{~h}$ at $37^{\circ} \mathrm{C}$, reactions were terminated by addition of $200 \mu \mathrm{L}$ ACN. Samples were then chilled at $-20{ }^{\circ} \mathrm{C}$ for $10 \mathrm{~min}$ and centrifuged at $14,000 \times g$ for $5 \mathrm{~min}$. Then, $200 \mu \mathrm{L}$ of the supernatant were evaporated to dryness using a Labconco Centrivap Benchtop Vacuum Concentrator (Labconco, USA) and reconstituted in $100 \mu \mathrm{L}$ water/ACN $(9: 1, v / v)$ for LC-MS/MS analysis. Glucuronidation experiments with the recombinant UGTs were carried out in four independent experiments.

\section{Animals and study design}

All procedures related to the animal experiment were performed according to Austrian law and following the European Guidelines for the Care and Use of Animals for Research Purpose (European Commission 2010). The experiment was approved by the office of the Lower Austrian Region Government, Group of Agriculture and Forestry, Department of Agricultural Law (approval code LF1TVG-39/050-2017) and carried out at the Center of Applied Animal Nutrition (Biomin Holding GmbH, Tulln, Austria).

Six crossbred piglets (sow: Landrace x Large White, boar: Pietrain; approximately 5 weeks old, $8.7 \pm 1.0 \mathrm{~kg}$, mixed sex) were obtained from a local swine producer. Piglets were housed individually in metabolic cages, had free access to water and were allowed to acclimatize for 5 days. Feed was provided twice daily and withdrawn after $30 \mathrm{~min}$ to monitor feed intake. Prior to the start of the experiment, the feed was tested for mycotoxin contamination by LC-MS/MS (Malachova et al. 2014). Low levels of CUL ( $20 \mu \mathrm{g} / \mathrm{kg}), 5$-hydroxyculmorin $(107 \mu \mathrm{g} / \mathrm{kg}), 15$-hydroxyculmorin $(67 \mu \mathrm{g} / \mathrm{kg})$ and DON $(79 \mu \mathrm{g} / \mathrm{kg})$ were present in the diet, whereas other relevant mycotoxins (e.g., aflatoxin $\mathrm{B}_{1}$, fumonisin $\mathrm{B}_{1}$, ochratoxin A, etc.) were not detected.

Piglets received 50\% PEG 300 (solvent control) and CUL ( $150 \mu \mathrm{g} / \mathrm{kg}$ body weight) by gavage on day 1 and 7 . To this end, respective solutions were orally administered via polyvinyl chloride catheters. Urine and feces of individual piglets were collected $0-8 \mathrm{~h}, 8-24 \mathrm{~h}$ and $24-28 \mathrm{~h}$ after each of the treatments. Samples were stored at $-20^{\circ} \mathrm{C}$ until analysis.

\section{LC-MS measurements}

Pig urine samples were diluted to $0.2 \mathrm{mM}$ creatinine with $\mathrm{MeOH} /$ water $(50 / 50, \mathrm{v} / \mathrm{v})$ and centrifuged at $14,350 \times \mathrm{g}$ for $10 \mathrm{~min}$. Measurement of liver microsome samples and pig urine samples was carried out on a 1290 Infinity series UHPLC system (Agilent Technologies, Waldbronn, Germany) coupled to a $6500+$ QTrap mass spectrometer equipped with an IonDrive TurboV source (SCIEX, Foster City, CA, USA). Analytes were separated in gradient elution mode on a Kinetex C18 column $(150 \times 2.1 \mathrm{~mm}$, $2.6 \mu \mathrm{m}$, Phenomenex, Aschaffenburg, Germany). Mobile phase A was water/acetic acid $(99.9 / 0.1, \mathrm{v} / \mathrm{v})$, mobile phase B was composed of ACN/acetic acid (99.9/0.1, v/v). The following linear gradient was used: $0.0-0.5 \mathrm{~min}$ : $5 \% \mathrm{~B}$, 0.5-7.0 min: linear increase to $15 \% \mathrm{~B}, 7.0-14.0 \mathrm{~min}$ : linear increase to $90 \% \mathrm{~B}, 14.1-16.0 \mathrm{~min}: 100 \% \mathrm{~B}, 16.1-19.0 \mathrm{~min}$ : re-equilibration at $5 \% \mathrm{~B}$. The flow rate was $250 \mu \mathrm{L} / \mathrm{min}$, the column temperature was $30{ }^{\circ} \mathrm{C}$ and the injection volume was $3 \mu \mathrm{L}$. Mass spectrometric detection was performed in negative mode after electrospray ionization. The source parameters were: source temperature $400{ }^{\circ} \mathrm{C}$, ion spray voltage $-4500 \mathrm{~V}$, curtain gas $35 \mathrm{psi}$, ion source gas $160 \mathrm{psi}$ and ion source gas 240 psi. Selected reaction monitoring mode was chosen as scan type and the following transitions were used: CUL-11-GlcAc quantifier $m / z$ 413.5 $\rightarrow m / z 113.1$ [declustering potential (DP) $-50 \mathrm{~V}$, collision energy (CE) $-40 \mathrm{~V}$ ], CUL-11-GlcAc qualifier_1 $\mathrm{m} / \mathrm{z} 413.5 \rightarrow \mathrm{m} / \mathrm{z} 175.1$ $(\mathrm{DP}-50 \mathrm{~V}, \mathrm{CE}-35 \mathrm{~V})$, CUL-11-GlcAc qualifier_2 $\mathrm{m} / \mathrm{z}$ $413.5 \rightarrow m / z 219.2(\mathrm{DP}-50 \mathrm{~V}, \mathrm{CE}-50 \mathrm{~V})$; CUL quantifier $m / z, 297.4 \rightarrow m / z 59.0$ (DP $-50 \mathrm{~V}, \mathrm{CE}-35 \mathrm{~V}$ ). Analyst software version 1.6.3 (SCIEX) was used for instrument control and data analysis. CUL-11-GlcAc eluted at $11.40 \mathrm{~min}$, CUL at $12.89 \mathrm{~min}$. In urine diluted to $0.2 \mathrm{mM}$ creatinine, matrix effects of CUL-11-GlcAc and CUL were 96 and 95\%, respectively. The limits of detection (LODs, signal-noise ratio 3:1) for CUL-11-GlcAc and CUL in pure solvent standard solution were $0.1 \mathrm{ng} / \mathrm{mL}$ and $2 \mathrm{ng} / \mathrm{mL}$, respectively. In urine diluted to $0.2 \mathrm{mM}$ creatinine, the LOD of CUL-11-GlcAc was $0.8 \mathrm{ng} / \mathrm{mL}$ and the LOD of CUL was $2.5 \mathrm{ng} / \mathrm{mL}$. Limits of quantification (signal to noise ratio 10:1) were by the factor 3.3 higher than LODs.

All samples obtained from the glucuronidation assay using the recombinant enzymes UGT 2B4 and UGT 2B7 and also the human urine sample were measured by LC-HRMS applying the following method: after reconstitution, the samples were analyzed by an LC-HRMS method using a UHPLC Vanquish system hyphenated with a Q Exactive HF high-resolution mass spectrometer equipped with a heated electrospray ionization (hESI) source (all from Thermo Fisher Scientific, Waltham, USA). Chromatographic separation was achieved on a reversed-phase Acquity UPLC HSS T3 column $(100 \times 2.1 \mathrm{~mm}, 1.8 \mu \mathrm{m}$, Waters, Milford, USA) protected by a HSS T3 VanGuard pre-column at $40{ }^{\circ} \mathrm{C}$. At a constant flow rate of $0.4 \mathrm{~mL} / \mathrm{min}$, a linear gradient was employed with water (A) and ACN (B), both containing $0.1 \%$ acetic acid. After an initial hold time of $2 \mathrm{~min}$ at $10 \% \mathrm{~B}$, the gradient was raised to $50 \% \mathrm{~B}$ at minute 6 and $100 \% \mathrm{~B}$ at minute 7 . After $2 \mathrm{~min}$ at $100 \% \mathrm{~B}$, the column 
was re-equilibrated at $10 \% \mathrm{~B}$ for $1 \mathrm{~min}$. A sample volume of $2 \mu \mathrm{L}$ was injected by the autosampler which was maintained at $4{ }^{\circ} \mathrm{C}$. The following settings were used: negative ionization mode, capillary temperature, $325^{\circ} \mathrm{C}$; vaporizer temperature, $400{ }^{\circ} \mathrm{C}$; sheath gas, 60 arbitrary units (a.u.); auxiliary gas, 20 a.u.; sweep gas, 3 a.u.; capillary voltage, $3 \mathrm{kV}$. The instrument was operated in profile mode (scan range, $m / z 60-900$ ) with a resolving power of 120.000 full width at half maximum and automatic gain control setting of $3 \times 10^{6}$ with a maximum injection time of $100 \mathrm{~ms}$. The LOD for DON-3-GlcA and DON-15-GlcA (peak area 5000 a.u.) was estimated based on the smallest peak detected within the respective measurement sequence. For data evaluation, Xcalibur $^{\mathrm{TM}}$ (version 3.0, Thermo Scientific) and TraceFinder $^{\mathrm{TM}}$ (version 3.3, Thermo Scientific) software were used. The general status of the instrument was regularly checked by the measurement of blank and quality control samples before and after the sequence.

The diluted human urine sample, obtained from pregnant women from Croatia (Sarkanj et al. 2013; Warth et al. 2016), was analyzed by the LC-HRMS full scan method to evaluate if CUL-11-GlcA may be found in human specimen. To verify the identity of the conjugate, additional MS/MS spectra of the urine sample and the reference standard were performed.

\section{Cell culture and treatment}

The human colorectal adenocarcinoma cell line HT-29 was purchased from the German Collection of Microorganisms and Cell Cultures (DSMZ, Braunschweig, Germany), the human liver hepatocellular carcinoma cells HepG2 and the human colorectal adenocarcinoma cell line Caco-2 from the American Type Culture Collection (ATCC, Manassas, USA). For HT-29 and Caco-2 cell cultivation Dulbecco's Modified Eagle's Medium and for HepG2 cells RPMI 1640 medium was used. All three basal media formulations were supplemented with $10 \%(\mathrm{v} / \mathrm{v})$ heat-inactivated fetal calf serum and $1 \%(\mathrm{v} / \mathrm{v})$ penicillin/streptomycin $(50 \mathrm{U} / \mathrm{mL})$. Caco- 2 culture medium was additionally supplemented with $1 \%$ potassium pyruvate and $0.01 \mathrm{mg} / \mathrm{mL}$ insulin-transferrin-selenium. Culture media and supplements were purchased from GIBCO Invitrogen (Karlsruhe, Germany). For cell cultivation and treatments, humidified incubators at $37{ }^{\circ} \mathrm{C}$ and $5 \% \mathrm{CO}_{2}$ were used. Cells were routinely tested for the absence of mycoplasma contamination and used for experiments at passages 9-25. CUL, DON and their combinations were added to the incubation solutions, resulting in final solvent concentrations of $1 \%$ (v/v) LC-MS grade water and $1 \%(\mathrm{v} / \mathrm{v})$ DMSO. Measurements of combinatory effects were always performed in parallel to the single substance on the same 96-well plate, to maximize comparability of the data and to allow an accurate calculation of the combinatory effects.

\section{Quantitative analysis of UGT gene transcription}

Gene transcription of UGT 2B4 and UGT 2B7 in three different human cancer cell lines (HepG2, HT-29 and Caco-2) and the potential impact of CUL and DON on UGT transcription levels was analyzed by quantitative real-time PCR (qPCR). Cells were seeded in 24-well plates (HepG2: 52,500 cells/ well; HT-29: 30,000 cells/well; Caco-2: 80,000 cells/well) and allowed to grow for $48 \mathrm{~h}$. After respective incubations, total RNA was extracted using RNeasy ${ }^{\circledR}$ Mini Kits (Qiagen, Hilden, Germany) and reversed transcribed into complementary DNA (cDNA) by QuantiTect ${ }^{\circledR}$ Reverse Transcription Kit (Qiagen) according to the supplier's protocols. Amplification of the cDNA samples in the presence of genespecific primers (QuantiTect ${ }^{\circledR}$ Primer Assays, Qiagen) and QuantiTect ${ }^{\circledR}$ SYBR Green Master Mix (Qiagen) was performed in technical duplicates using a StepOnePlus ${ }^{\mathrm{TM}}$ System (Applied Biosystems, Foster City, USA). The following primer assays were used: $\beta$-actin (ACTB1, Hs_ACTB1_1_ SG, QT00095431); glyceraldehyde 3-phosphate dehydrogenase (GAPDH, Hs_GAPDH_2_SG, QT01192646); UGT 2B4 (Hs_UGT2B4_1_SG; QT00029456); UGT 2B7 (Hs_ UGT2B7_2_SG, QT01667554). A universal PCR protocol was applied including 15 -min enzyme activation at $95^{\circ} \mathrm{C}$, 40 cycles of $15 \mathrm{~s}$ at $94{ }^{\circ} \mathrm{C}, 30 \mathrm{~s}$ at $55^{\circ} \mathrm{C}$ and $30 \mathrm{~s}$ at $72{ }^{\circ} \mathrm{C}$. StepOnePlus ${ }^{\circledR}$ software (version 2.3, Applied Biosystems, USA) was used for fluorescence signal quantification and further data analysis. Of each tested sample, at least three independent experiments were performed. Presented transcript data were normalized to the mean of transcript levels of endogenous control genes (ACTB1, GAPDH) applying if possible and necessary the $\Delta \Delta \mathrm{Ct}$-method (Schmittgen and Livak 2008). Respective $2^{-\Delta \mathrm{Ct}}$ data are shown as Online Resource (Fig. S5a-c).

\section{Combinatory effects on cell viability- sulforhodamine B assay}

To determine combinatory effects of CUL with DON on cell viability, the sulforhodamine B (SRB) assay according to Skehan et al. (1990) was applied. For this purpose, reactions containing different concentrations of CUL and the respective DON concentration at a constant substance ratio of 10:1 were incubated. In both cell lines, 24-h incubations were conducted; whereas in HT-29 combinations, additionally experiments applying 48-h toxin treatment were assessed. HT-29 and HepG2 cells were seeded into 96-well plates and allowed to grow for $72 \mathrm{~h}$. Cells were incubated for $24 \mathrm{~h}$ or $48 \mathrm{~h}$ with CUL and DON (CUL $0.01-100 \mu \mathrm{M}$; DON $0.01-10 \mu \mathrm{M}$ ) and the respective 
combinations. Subsequently, the cells were rinsed with pre-warmed phosphate-buffered saline, fixed with 5\% (v/v) trichloroacetic acid incubated at $4{ }^{\circ} \mathrm{C}$ for $30 \mathrm{~min}$. Afterwards, cells were washed four times with water, plates were dried overnight at room temperature and then stained for $1 \mathrm{~h}$ using a solution of $0.4 \%(\mathrm{w} / \mathrm{v}) \mathrm{SRB}$ in $1 \%(\mathrm{v} / \mathrm{v})$ acetic acid. To remove the remaining staining solution, cells were washed twice with water and $1 \%(\mathrm{v} / \mathrm{v})$ acetic acid solution. Then, plates were dried at room temperature in the dark. Finally, $10 \mathrm{mM}$ Tris buffer $(\mathrm{pH} 10 ; 100 \mu \mathrm{L}$ per well) was used to dissolve the dye and single wavelength absorbance was read at $570 \mathrm{~nm}$ using a Cytation 3 Imaging Multi Mode Reader (BioTek, Bad Friedrichshall, Germany). A solution of $1 \%(\mathrm{v} / \mathrm{v})$ triton X-100 served as positive control. Cell-free blank values were subtracted and measured data were referred to the respective solvent control. Combinatory cell viability data were compared to single treatments and to a mathematically determined expected value (EV; see "Data visualization and statistical analysis of combinatory effects").

\section{Data visualization and statistical analysis of combinatory effects}

Combinatorial interactions of two or more substances are present if the experimentally determined effect differs from the "additive effect" of the two or more single compounds (Chou 2006). To assess interactions that do not follow a linear dose-response relationship, mathematical models must be applied to calculate this "additive effect". Chou's "multiple drug effect equation" (Chou 2006) is currently recognized as the most accurate model existing to describe these effects (Aichinger et al. 2018; Alassane-Kpembi et al. 2017; Vejdovszky et al. 2017). However, the determination of an $\mathrm{IC}_{50}$ value and, therefore, a measurable effect of at least $50 \%$ is a prerequisite for the application of this model. Since in some of our experimental setups this criterion was not fulfilled, the model of independent joint action (IJA) was chosen for the analysis of combinatory effects of CUL and its co-contaminant DON (Webb 1963). Applying this model, an EV is calculated for each combination taking into consideration the determined single effects via the formula: $f_{\mathrm{ab}}=f_{\mathrm{a}}+f_{\mathrm{b}}-f_{\mathrm{a}} f_{\mathrm{b}}$, with $f_{\mathrm{ab}}$ being the $\mathrm{EV}$, and $f_{\mathrm{a}}$ and $f_{\mathrm{b}}$ being the measured effects of the single substances. Then, the EV was compared to the measured combinatory data set applying two-tailed Student's $t$ test. In the glucuronidation assay, statistical differences between the determined single effects of DON and the combination with CUL in glucuronide formation were calculated applying two-tailed Student's $t$ test using for the combinatory data $50 \%$ relative standard deviation (RSD), defined as LOD. For statistical analysis and data visualization, Origin 2018 software (Northampton, USA) was used.

\section{Results}

\section{Inhibitory effect of CUL on in vitro glucuronidation of DON}

The ability of CUL to interfere with DON glucuronidation was assessed using two commercially available liver microsome preparations from human and rats. As expected, the main metabolite of DON incubated with liver microsomes from rats was DON-3-GlcA (data not shown). No significant concentration differences of DON-3-GlcA in the DON, CUL/ DON (1:1) and CUL/DON (1:5) groups were seen. Thus, it seems that CUL has no modulatory effect on the glucuronidation activity of rat liver microsomes. Interestingly, the picture was quite different using human liver microsomes (Fig. 2a, b). Only a small part of DON was glucuronidated, of which the major metabolite was DON-15-GlcA (Fig. 2a), formed about 3.5 times more than DON-3-GlcA (Fig. 2b). However, using the human microsomes, combinatory incubations resulted in a significant decrease in the concentration of both formed DON-glucuronides with increasing CUL concentrations. In the equimolar combinations, only $85 \%$ DON-15-glucuronide and $70 \%$ DON-3-glucuronide of the initial glucuronide formation were found. Applying fivefold molar excess of CUL resulted in about $50 \%$ inhibition.

In case of human recombinant UGTs, both UGT 2B isoforms tested (2B4 and 2B7), accepted DON as a substrate, leading to the formation of one glucuronide each (Fig. 2c, d), even though the activities of both recombinant enzymes for the respective glucuronide formation were low. UGT 2B4 primarily formed DON-15-GlcA (Fig. 2c), whereas UGT 2B7 solely catalyzed the formation of DON-3-GlcA (Fig. 2d).

Combinatory incubations of $100 \mu \mathrm{M}$ CUL together with $10 \mu \mathrm{M}$ DON resulted in reduced glucuronidation activity in the enzyme preparations. In the UGT 2B4 incubations, the DON-15-GlcA signal was significantly reduced to $3 \%$ of the initial glucuronide formation, whereby signal detection was possible in only one of the four replicates very close to the method's detection limit. In UGT 2B7, which showed lower glucuronidation activity with DON alone, the combination with CUL decreased glucuronidation to a level not detectable by the applied method.

When incubated with $100 \mu \mathrm{M} \mathrm{CUL}$, both UGT 2B isoforms also led to the formation of a CUL-11-GlcA (Fig. 1c), firstly identified in in vitro enzyme incubations. CUL-11-GlcA formation was not affected by the presence of DON. 


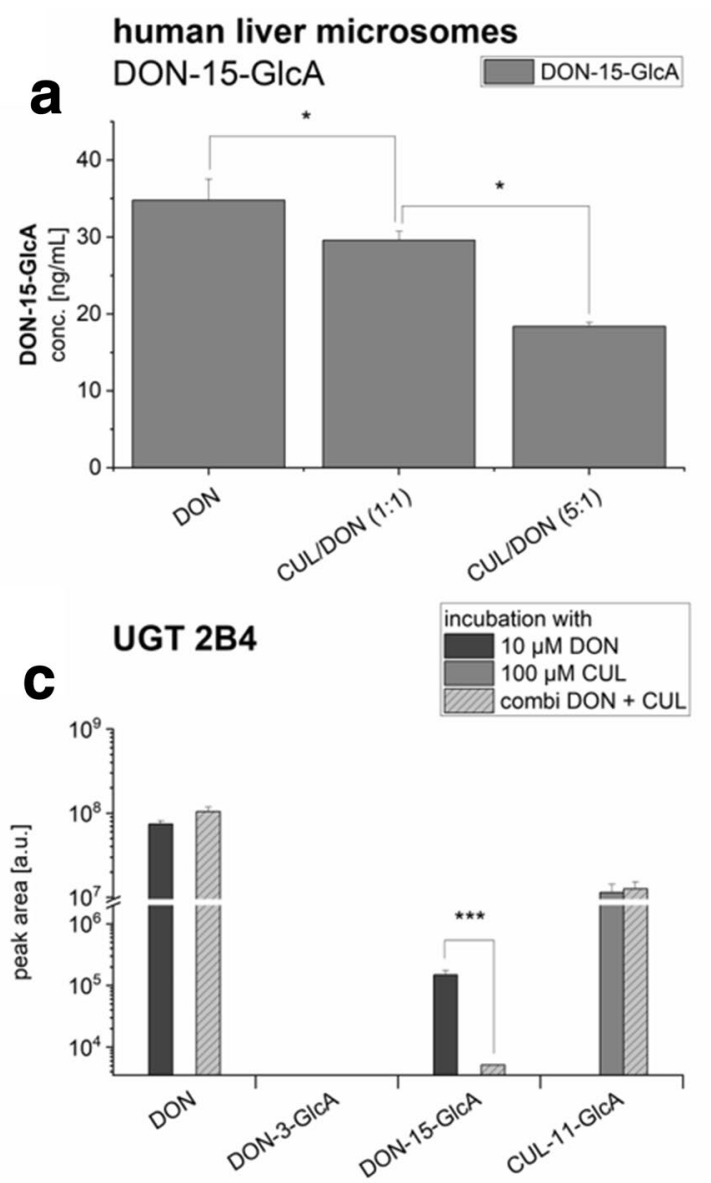

Fig. 2 Glucuronidation activity of (a and $\mathbf{b}$ ) human liver microsomes and of (c) the recombinant human UGT 2B4 and (d) UGT 2B7, mainly responsible for conjugation of $\mathrm{DON}$ and the respective combinatory effects with CUL. Data are expressed as mean values \pm SD of four independent UGT incubations and of five independent microso-

\section{Differences in UGT gene transcription in HepG2, HT-29 and Caco-2 cells}

Encouraged by these results, we set out to test whether an interaction between DON and CUL is also evident at the level of cell lines in toxicity assays. We first tested whether the relevant UGTs are expressed in the cell lines used, and whether the presence of DON or CUL had an effect on expression of the respective genes. Messenger RNA (mRNA) levels of the two UGT isoforms responsible for DON glucuronidation in three different cancer cell lines were investigated by qRT-PCR and are depicted relative to UGT 2B4 mRNA expression in HepG2 cells (Fig. 3). Transcription levels of UGT 2B4 in HepG2 and Caco-2 were found to be similar. In Caco-2, mRNA levels of UGT 2B4 were only $2.60 \pm 2.67$-fold higher than in HepG2. In contrast, in HT-29, mRNA of UGT 2B4 was found only at low levels in comparison to the other two cell lines, as a

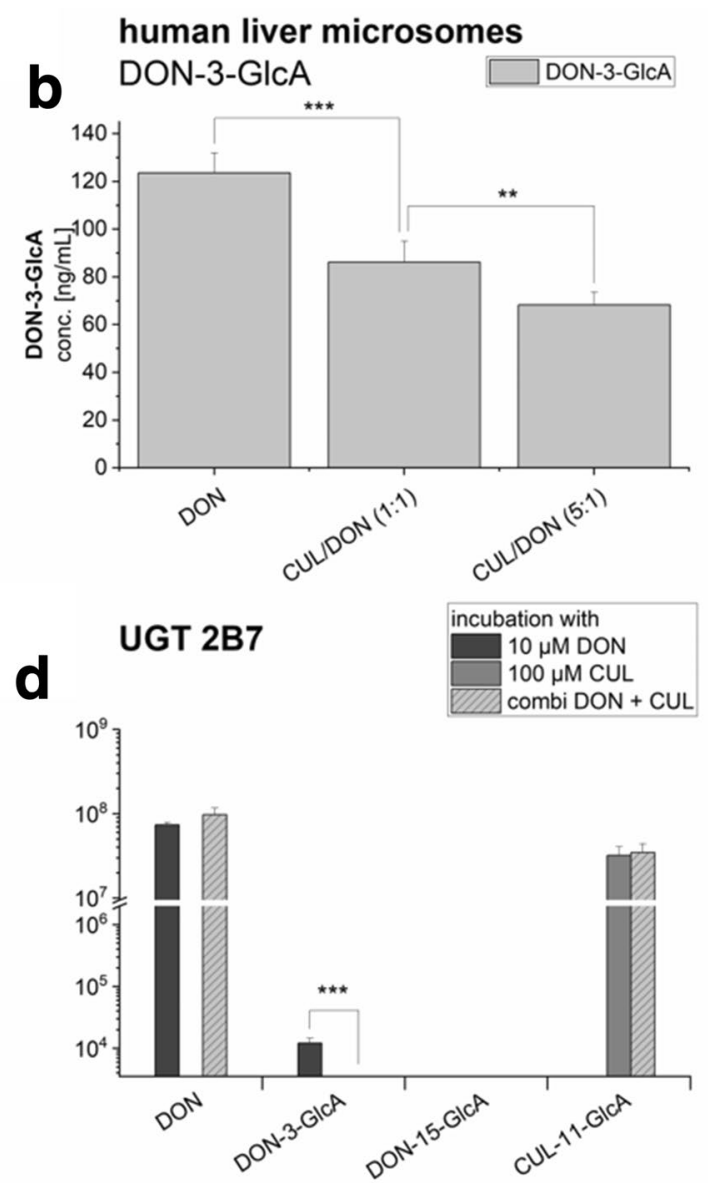

mal incubations. Significant differences to the respective combinatory value are indicated with $(*)$ representing $p<0.05,(* *)$ representing $p<0.01$ and $(* * *)$ representing $p<0.001$. For the statistical analysis of the recombinant UGTs 50\% RSD, defined as LOD, were used

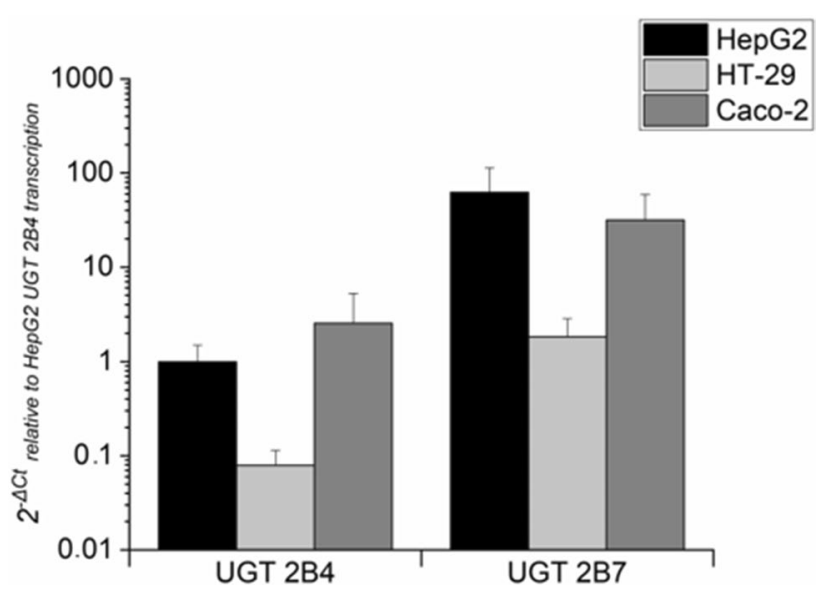

Fig. 3 Gene transcription levels of UGT 2B4 and UGT 2B7 in HepG2, HT-29 and Caco-2 cells measured by qPCR. Transcription data are normalized to the gene expression levels of UGT 2B4 in HepG2. Data are expressed as mean values \pm SD of at least four independent experiments performed in technical duplicates 


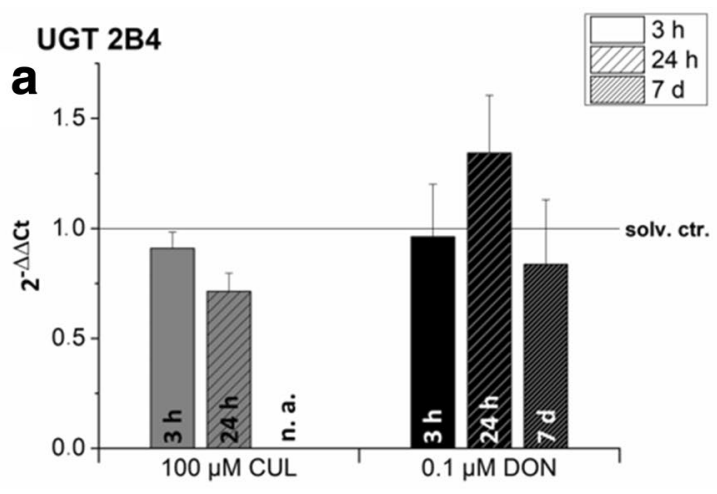

Fig. 4 Impact of CUL and DON exposure on gene transcription levels of (a) UGT 2B4 and (b) UGT 2B7 in HT-29 cells after 3-h, 24-h and 7-day incubation measured by qPCR. Transcription data are normalized to the respective solvent controls (solv. ctr., solid line). Due to a lack of substance availability of CUL 7-day treatments have not been assessed in this case (n. a.). As sub-toxic substance concentrations were applied in this experiment, transcript levels are not

$0.07 \pm 0.03$-fold expression of this isoform was determined. Transcript levels of UGT 2B7 were much higher in the analyzed cell lines: about 62 -fold in HepG2, only 1.8-fold in HT-29 and around 32-fold in Caco-2. Comparing the different UGT transcription levels of each cell line, in HepG2 cells, UGT 2B7 levels were comparably high. In HT-29, UGT 2B4 was determined to be the least transcribed isoform under the tested conditions. In Caco-2, a similar transcription pattern as in HepG2 cells was found.

\section{Impact of sub-toxic concentrations on UGT gene transcription}

The human colon cancer cell line HT-29, known to effectively glucuronidate other mycotoxins such as alternariol and alternariol methyl ether (Pfeiffer et al. 2007), was selected exemplarily for further analysis of the UGT transcription levels and cytotoxicity studies (see "Combinatory cytotoxic effects"). qRT-PCR was used to investigate the modulatory effect of sub-toxic concentrations of CUL $(100 \mu \mathrm{M})$ and DON $(0.1 \mu \mathrm{M})$ after 3-h, 24-h and long-term exposure on UGT mRNA levels (Fig. 4a, b). Only marginal impact of short-term CUL exposure ( $3 \mathrm{~h}$ ) on UGT transcription levels could be determined, resulting in a slightly increased mRNA concentration of UGT 2B7. However, 24-h incubation with $100 \mu \mathrm{M}$ CUL resulted in a decrease in the transcription levels of both UGT isoforms tested. Due to limited availability (in-house purification of CUL), long-term cell exposure for 7 days with CUL was not tested.

Incubations with DON for $3 \mathrm{~h}$ caused a tentative reduction of the UGT 2B7 transcription level (Fig. 4b). While after 24-h cell exposure, UGT 2B4 transcript levels were increased to $1.3 \pm 0.2$, UGT $2 \mathrm{~B} 7 \mathrm{mRNA}$ levels remained

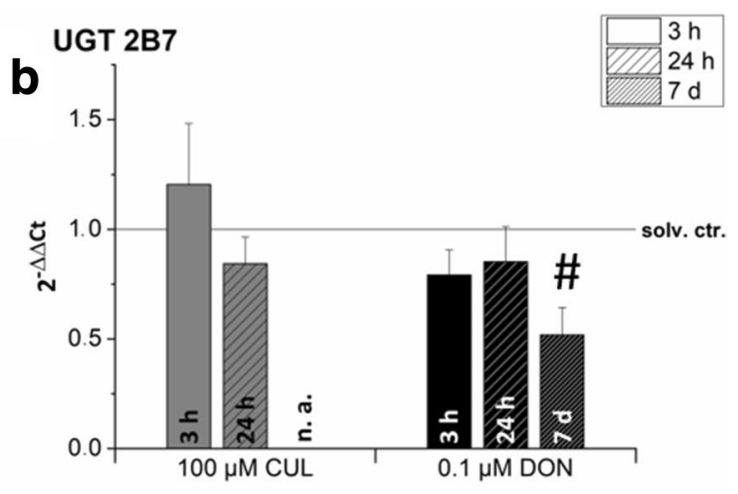

affected by cytotoxicity. Data are expressed as mean values \pm SD of at least three independent experiments performed in technical duplicates. Data were tested by Kruskal-Wallis ANOVA to compare different time-points and one-sample $t$ test to assess differences to the solvent control. \# indicates significant differences in comparison to the solvent control level $(p<0.05)$

below solvent control level. Long-term treatment of HT-29 cells for 7 days caused a significant reduction of the transcription level in case of UGT 2B7 in comparison to the solvent control, resulting in the following relative transcript level: $0.5 \pm 0.1$ (Fig. 4b).

\section{Combinatory cytotoxic effects}

In both cell lines, HT-29 and HepG2, CUL $(0.1-100 \mu \mathrm{M})$ did not cause any statistically significant cytotoxic effect in the SRB assay after 24-h incubation (Fig. 5a, b). Since a constant 10:1 ratio has already been used in the glucuronidation assay (see "Inhibitory effect of CUL on in vitro glucuronidation of DON") and as DON concentrations $\geq 10 \mu \mathrm{M}$ are known to cause strong cytotoxic effects after 24-h incubations, combinations with CUL were performed in the concentration ratio 10:1 (CUL:DON; Fig. 5a-c). In both cell lines, DON mediated similar cytotoxic effects, resulting in a statistically significant reduction of the cell viability at DON concentrations $\geq 1 \mu \mathrm{M}$. Combinations of CUL and DON caused similar cytotoxic effects to the ones mediated by DON alone and none of the tested combinations differed significantly from the mathematically calculated EVs.

To assess combinatory effects of CUL on DON-induced cytotoxicity after longer incubation times, HT-29 cells were treated for $48 \mathrm{~h}$. Nevertheless, even cell treatments for $48 \mathrm{~h}$ did not cause significant cytotoxic effects of CUL, nor combinatory effects of CUL and DON (Fig. 5c). Thus, with respect to cytotoxicity, no significant effects of the binary mixtures in comparison to the single treatments with DON or the calculated EV were observed. 
Fig. 5 Combinatory effects of CUL with DON on cell viability of HT-29 (24-h incubation: a; 48-h incubation: c) and HepG2 cells (24-h incubation: b) in the sulforhodamine B assay. Combinations of CUL and DON were combined 10:1. $1 \%$ water (LC-MS grade) $+0.5 \%$ DMSO served as solvent controls (solid line). Data are expressed as mean values \pm SD of at least five independent experiments performed in triplicates normalized to the respective solvent control. $1 \%$ triton-X 100 was used as positive control (TX100). Significant differences to the respective lowest tested concentration are indicated in the graphs with (b) for DON and (c) for the combination (exponents represent: (1) $p<0.05$ and (2) $p<0.01$ )
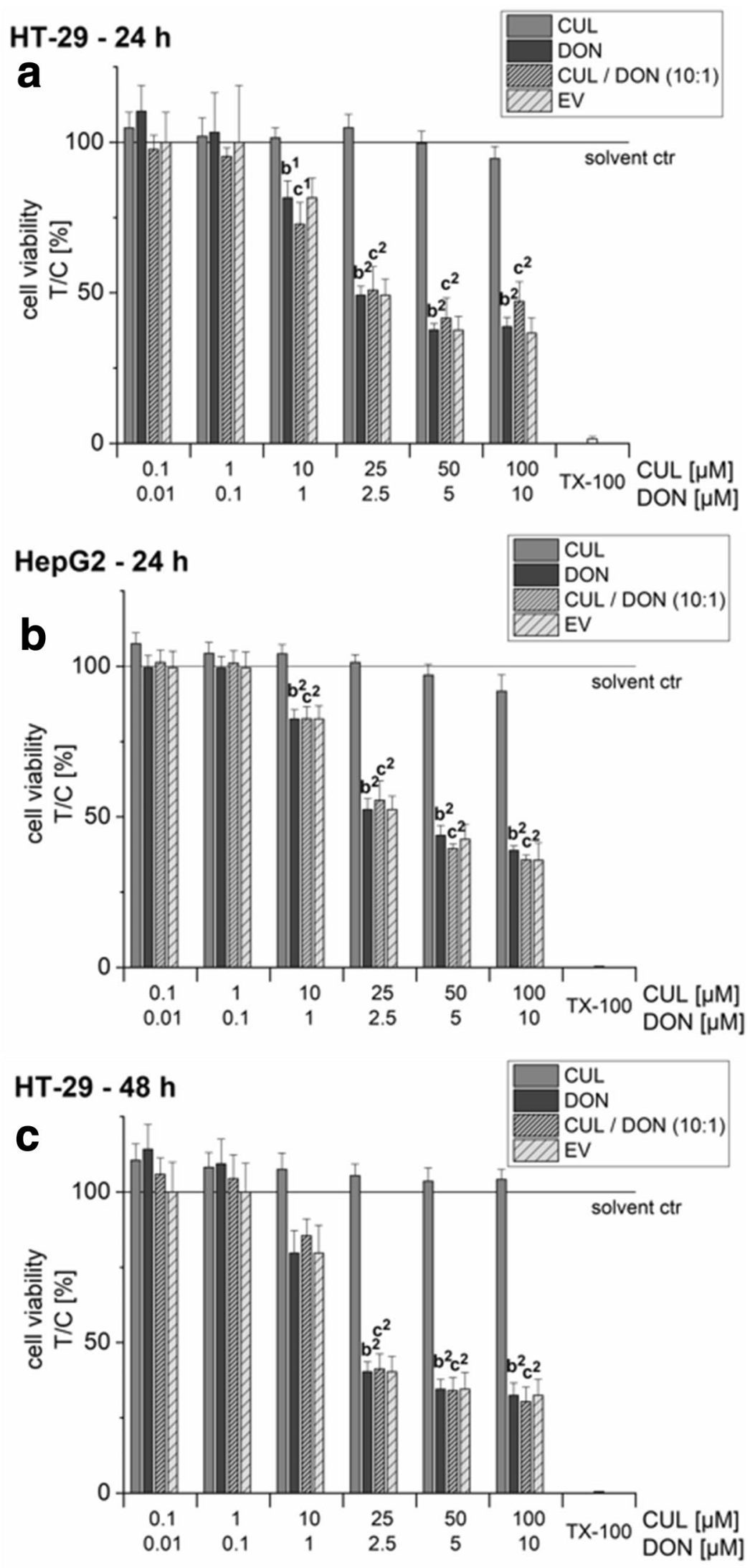


\section{Formation of CUL-11-GICA in vivo}

Urine samples of the piglet trial were diluted to the same concentration of creatinine $(0.2 \mathrm{mM})$ and concentrations of CUL and CUL-11-GlcA were determined by LC-MS/MS. CUL-11-GlcA eluted at $11.40 \mathrm{~min}, \mathrm{CUL}$ at $12.89 \mathrm{~min}$ and a potential further CUL-GlcA at $4.27 \mathrm{~min}$. In urine diluted to $0.2 \mathrm{mM}$ creatinine, matrix effects of CUL-11-GlcA and CUL were 96 and 95\%, respectively. The LODs (signal to noise ratio 3:1) for CUL-11-GlcA and CUL in pure solvent standard solution were $0.1 \mathrm{ng} / \mathrm{mL}$ and $2 \mathrm{ng} / \mathrm{mL}$, respectively. In urine diluted to $0.2 \mathrm{mM}$ creatinine, the LOD of CUL-11GlcA was $0.8 \mathrm{ng} / \mathrm{mL}$ and the LOD of CUL was $2.5 \mathrm{ng} / \mathrm{mL}$. Limits of quantification (signal-noise ratio 10:1) were by the factor 3.3 higher than LODs. Figure 6 shows chromatograms of CUL-11-GlcA and CUL in pure solvents (Fig. 6a) and in a pig urine sample (Fig. 6b).

As with the recombinant UGT enzymes and (human and rat) liver microsomes, CUL was also readily glucuronidated in vivo to CUL-11-GlcA by pigs. In measured urine samples from four animals, the concentration of CUL-11-GlcA was higher than of CUL (maximum CUL-11-GlcA/CUL ratio: 8.7, average ratio 6.3). In urine samples of two animals, no CUL-11-GlcA was detected. One likely explanation for the latter is that insufficient separation of urine and feces in the metabolic cages led to hydrolysis of the formed glucuronides by gut microbes during the sampling period.

CUL-11-GlcA was further detected in a human urine sample obtained from pregnant women in Croatia (Sarkanj et al. 2013; Warth et al. 2016) (Online Resource: Fig. S4).
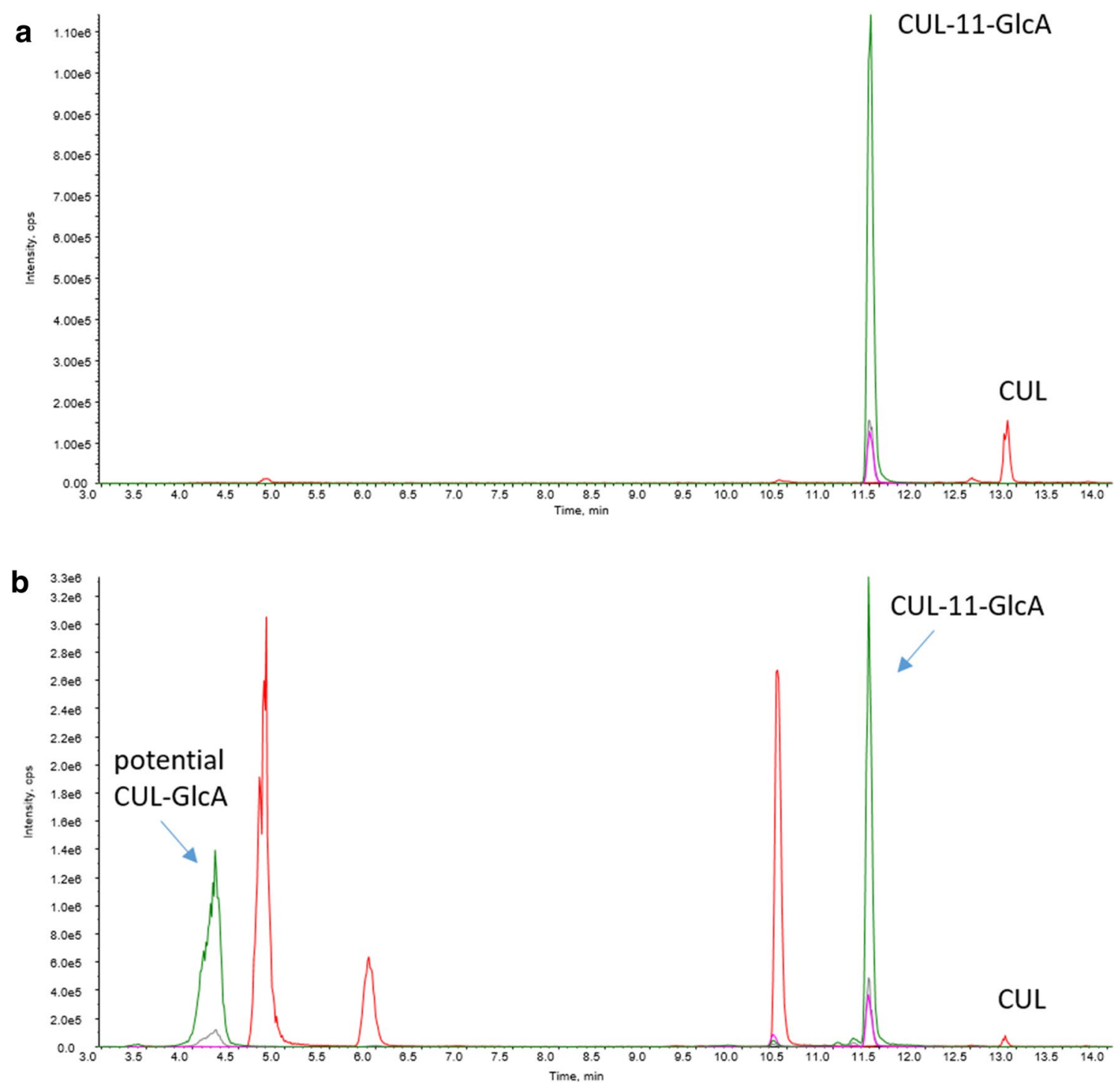

Fig. 6 LC-MS/MS chromatograms of CUL-11-GlcA and CUL (a) in pure solvent standard solution (100 ng/mL of both compounds) and (b) in a piglet urine sample (concentration of CUL-11-GlcA in urine: $5.38 \mathrm{mg} / \mathrm{L}$, concentration of CUL in urine: $0.71 \mathrm{mg} / \mathrm{L}$ ) 
Retention time and MS/MS spectra (Fig. 6, Online Resource: Fig. S3 and S4) allowed the identification of CUL-11-GlcA as novel pig and human metabolite.

\section{Discussion}

Mycotoxins not only cause substantial economic losses due to contaminated food, feed and loss of animal productivity, but also pose a serious health threat to both humans and livestock. Numerous studies tried to characterize the toxic potential and mechanistic activities of various Fusarium mycotoxins (Alshannaq and Yu 2017; Fraeyman et al. 2017; Pestka 2010b). Nevertheless, so far this study is, to the best of our knowledge, the first to address combinatory effects of the two co-occurring Fusarium metabolites DON and CUL in human cell models. CUL, previously reported to have limited toxic potential in mammals (Dowd et al. 1989; Miller and MacKenzie 2000; Pedersen and Miller 1999; Prelusky et al. 1989; Rotter et al. 1992), was found to inhibit the metabolic activity of purified plant UDP-glucosyltransferases (Michlmayr et al., unpublished). To investigate interactions of CUL and DON on DON-detoxifying, mammalian enzymes, glucuronidation activities of human liver microsomes and two human UGTs were determined. Using human liver microsomes, significantly lower levels of DON-glucuronides were found in the presence of CUL in a concentration-dependent manner (Fig. 2a, b). Regarding the two tested UGT isoforms, UGT 2B4 and 2B7, combinations with CUL led in both cases to conjugate concentrations near or even below the method's detection limit (Fig. 2c, d). Furthermore, we confirmed that DON-15-GlcA is predominantly formed by UGT 2B4 and that DON-3-GlcA formation is mainly catalyzed by UGT 2B7 (Maul et al. 2015). In accordance with Maul et al. (2015), only low glucuronidation activities were observed by both UGTs.

In the course of the in vitro enzyme experiments, a new CUL metabolite, CUL-11-GlcA, was identified and characterized. This finding argues presumably for a competitive inhibition of the UGTs, as the terpenoid CUL and DON might compete for the same binding site on the enzyme. However, CUL-11-GlcA was not only detected after incubation with UGT 2B4 and 2B7 in vitro (Fig. 2), but also identified as a novel in vivo metabolite in pig urine samples and in a human urine sample obtained from pregnant women in Croatia (Fig. 6; Online Resource: Fig. S4) (Sarkanj et al. 2013; Warth et al. 2016). This sample has been demonstrated before to contain high concentrations of DON $(275 \mu \mathrm{g} / \mathrm{L})$ and of its metabolites DON-3-GlcA $(298 \mu \mathrm{g} / \mathrm{L})$, DON-15GlcA $(1238 \mu \mathrm{g} / \mathrm{L})$, and DON-3-sulfate $(58 \mu \mathrm{g} / \mathrm{L})($ Sarkanj et al. 2013; Warth et al. 2016). Furthermore, a second CULGlcA was detected in the pig urine sample, which due to a lack of reference standard could be only tentatively identified as CUL-8-GlcA (Fig. 6).

In cell culture experiments, we aimed to further evaluate potential synergistic toxic effects of DON and CUL probably resulting from the UGT inhibition. To select in this respect appropriate cell lines, expressing the two UGT isoforms of interest, three well-known cancer cell lines (HepG2, HT-29 and Caco-2) were tested for their UGT transcription levels (Fig. 3). Even though mRNAs of both isoforms were present in all the addressed cell lines, expression levels differed substantially when comparing the three cell models, but also among the different isoforms. So far, UGT mRNA expression levels of these cell lines have not been compared, even though numerous studies investigated already UGT expression levels in human tissues, focusing mainly on the liver and the gastrointestinal tract (Court et al. 2012; Izukawa et al. 2009; Ohno and Nakajin 2009; Strassburg et al. 2000; Tukey and Strassburg 2000; Wu et al. 2011). As all three selected cell lines are commonly used for various toxicological studies and also to investigate xenobiotic and drug metabolism in vitro (Akbari et al. 2017; Bohets et al. 2001; Weaver et al. 2017), this characterization of UGT transcription levels is of crucial importance for the scientific community. A study, using real-time PCR to generate a quantitative expression level profile of the UGTs in 26 adult and 3 fetal tissues, confirmed that liver is the organ containing the highest levels of UGT mRNAs, among which UGT 2B4 was the most abundant isoform (40\% of total UGT mRNA content; up to $90 \%$ in fetal liver) (Court et al. 2012). Ohno and Nakajin (2009) analyzed beyond liver tissue extrahepatic mRNA levels of various UGT isoforms. Intestinal tissue expressed predominantly UGT 1A1, 1A10, 2B7, 2B15 and 2B17. Relatively low levels of various UGTs were reported in esophageal tissue and even in steroidogenic tissues, such as breast, prostate, heart and adrenal gland (Ohno and Nakajin 2009). However, most transcript profiles of UGTs in human tissue-derived cell lines are not consistent with those in corresponding tissue samples (Hart et al. 2010; Nakamura et al. 2008). Using semiquantitative reversetranscription PCR Nakamura et al. (2008) determined UGT mRNA levels from various cell lines including HepG2 and Caco-2. In HepG2, all UGT 2B isoforms tested were all highly expressed, whereas comparably low mRNA levels of most $1 \mathrm{~A}$ isoforms were determined. For Caco-2, similar UGT expression levels for UGT 1A1, 2B7 and 2B15 were elucidated; however, UGT 2B isoforms were less present in comparison to the levels in HepG2 cells (Nakamura et al. 2008). Studies comparing transcript levels or enzyme activities of HepG2 cells with those of human tissue samples, of primary human hepatocytes or of other liver cell lines, such as HepaRG, mainly reported in HepG2 cells lower UGT transcript levels and enzyme activities (Hart et al. 2010; Westerink and Schoonen 2007; Yokoyama et al. 2018). 
Performing a similar data analysis as Ohno and Nakajin (2009), normalizing the Ct-values obtained in our qRT-PCR experiments to the mean of transcript levels of endogenous control genes, multiplying by a factor $10^{4}$, relative values for UGT 2B4 of 5375 and 5026 and for UGT 2B7 of 6695 and 5781 can be obtained for HepG2 and HT-29, respectively. As Ohno and Nakajin (2009) reported in liver tissue samples values above 37,900 for UGT 2B4 expression, our results clearly show that the transcript levels of this UGT isoform in HepG2 cells are much lower than in the liver tissue. However, with respect to UGT 2B7, similar relative expression values to the ones calculated and reported above have been described by Ohno and Nakajin (2009).

Various studies in animal and in vitro models have demonstrated that the consumption of certain xenobiotics (e.g., aflatoxin $\mathrm{B}_{1}, \beta$-naphthoflavone, ethanol,etc.) may increase UGT levels and respective glucuronidation activities via different induction pathways (Court 2010; Hanioka et al. 2012, 2006; Kardon et al. 2000; Li et al. 2000). Since mRNA levels of the selected UGT isoforms were partly expressed at relatively low levels, exemplarily HT-29 cells were exposed to sub-toxic concentrations of DON $(0.1 \mu \mathrm{M})$ and CUL $(100 \mu \mathrm{M})$. We speculated that these short- and long-term incubations using respective UGT enzyme substrates might have modulatory or even inducing effects on UGT transcript levels (Fig. 4a, b). Incubations for $3 \mathrm{~h}$ only marginally affected UGT mRNA levels and after 24-h, UGT 2B4 was the only one slightly induced after DON incubation. Up to 2.5-fold inductions, such as reported by Hanioka et al. (2012) in HepG2 cells after 48-h aflatoxin $B_{1}$ treatment, could not be corroborated in this study. To date, similar studies assessing modulatory effects of DON or CUL treatment on UGT mRNA levels have not been described in literature so far.

Despite the fact that UGT transcription levels in all three cell lines were relatively low and even an extended exposure to sub-toxic substrate concentrations could not induce UGT mRNA expression, potential synergistic effects of the two Fusarium secondary metabolites on cell viability were assessed (Fig. 5). In HT-29 and HepG2 cells after $24 \mathrm{~h}$ and $48 \mathrm{~h}$, no significant interactions between CUL and DON could be determined. Hence, interactions between DON and CUL observed in planta (Michlmayr et al., unpublished) and by Dowd et al. (1989) in caterpillars, could not be confirmed in our cell models. While humans excrete in urine up to $90 \%$ of total DON as glucuronide conjugates, LC-MS/MS analysis of cell extracts could not detect DON-glucuronides in HT-29 and HepG2 cells (data not shown). However, in the same experiments, high glucuronide formation by both cell lines was observed for the Alternaria mycotoxin alternariol, known to be predominantly conjugated by UGT $1 \mathrm{~A} 1$ and UGT 1A9 (data not shown). Thus, as also transcription levels of UGT 2B4 were about tenfold lower than levels reported in liver tissue (Ohno and Nakajin 2009), potential inhibitory effects of CUL might be of minor importance for the overall toxicity in cell culture and might not be measurable at the determined endpoints. However, negative evidence from our cell culture experiments does not exclude a synergistic effect in the mammalian organism. Due to a lack in exposure and toxicokinetic data, one can only speculate, if relevant systemic concentrations of CUL and DON, at which competitive inhibition of UGTs might take place, can be reached by dietary toxin exposure. As technical issues rendered the findings of the above-mentioned in vivo study inconclusive, a respective animal study needs to be repeated to gain further insights into these CUL-DON interactions.

In conclusion, the present study reported for the first time CUL to partially inhibit the glucuronidation activity of human liver microsomes and recombinant UGTs. Furthermore, we were able to detect two novel CUL-glucuronides both in vitro, as well as, in vivo in pig and human urine samples. Even though in HT-29 and HepG2 cells this presumably competitive effect of CUL on DON glucuronidation did not induce considerably higher cytotoxicity in mixtures, which may be due to the limited glucuronide formation in the tested cell lines, in the human organism DON-glucuronide formation is the main detoxification reaction. Hence, to elucidate if this inhibitory mechanism and resulting combinatory effects are of importance in the mammalian organism and to gain further insight into systemic CUL concentrations and respective toxicokinetics, a more detailed characterization in vivo is required. This may contribute substantially to the discussion about classifying CUL not only as a secondary fungal metabolite but also as an "emerging mycotoxin". Furthermore, this study shows that we are still at the very beginning in the toxicological profiling of chemical mixtures, and underlines also that the assessment of drug-exposome interactions and their further understanding are of crucial importance.

Acknowledgements Open access funding provided by Austrian Science Fund (FWF). This research was supported by the Austrian Science Fund (FWF) via the special research project Fusarium (F3701, F3708, F3715 and F3718). Further financial support by the Austrian Federal Ministry of Science, Research and Economy, the Austrian National Foundation for Research, Technology and Development and BIOMIN Holding $\mathrm{GmbH}$ is acknowledged for funding the Christian Doppler Laboratory for Mycotoxin Metabolism. BIOMIN acknowledges funding by the Austrian Research Promotion Agency (Project 859,603). Moreover, we would like to thank the Austrian Research Promotion Agency (FFG) for financial support and Josef Bandion, Ida Gradner, Christina Gruber, Heinz Heidegger, Xiuqi Hu, Lukas Moser and Silvia Wein for practical support during the animal experiment. Furthermore, the authors would like to express their gratitude towards Dominik Braun, supporting the performance of qPCR experiments, towards the staff of the Mass Spectrometry Center at the Faculty of Chemistry at UNIVIE and Michaela Schwaiger and Laura Niederstätter for skillful technical support. 
Funding This research was supported by the Austrian Science Fund (FWF) via the special research project Fusarium (F3701, F3708, F3715 and F3718) and by the Austrian Research Promotion Agency (FFG). Financial support by the Austrian Federal Ministry of Science, Research and Economy, the Austrian National Foundation for Research, Technology and Development. Furthermore, BIOMIN Holding $\mathrm{GmbH}$ is acknowledged for funding the Christian Doppler Laboratory for Mycotoxin Metabolism. BIOMIN acknowledges funding by the Austrian Research Promotion Agency (Project 859,603).

\section{Compliance with ethical standards}

Conflict of interest FB has received research grants from BIOMIN Holding GmbH, the Austrian Science Fund (FWF), the Austrian Federal Ministry of Science, Research and Economy, the Austrian National Foundation for Research, Technology and Development.

Ethical approval All applicable international, national, and/or institutional guidelines for the care and use of animals were followed. All procedures performed in studies involving human participants were in accordance with the ethical standards of the institutional and/or national research committee and with the 1964 Helsinki declaration and its later amendments or comparable ethical standards.

Open Access This article is distributed under the terms of the Creative Commons Attribution 4.0 International License (http://creativeco mmons.org/licenses/by/4.0/), which permits unrestricted use, distribution, and reproduction in any medium, provided you give appropriate credit to the original author(s) and the source, provide a link to the Creative Commons license, and indicate if changes were made.

\section{References}

Aichinger G, Beisl J, Marko D (2018) The hop polyphenols xanthohumol and 8-prenyl-naringenin antagonize the estrogenic effects of Fusarium mycotoxins in human endometrial cancer cells. Front Nutr 5:1-11. https://doi.org/10.3389/fnut.2018.00085

Akbari P, Braber S, Varasteh S, Alizadeh A, Garssen J, Fink-Gremmels $\mathrm{J}$ (2017) The intestinal barrier as an emerging target in the toxicological assessment of mycotoxins. Arch Toxicol 91:1007-1029. https://doi.org/10.1007/s00204-016-1794-8

Alassane-Kpembi I, Puel O, Pinton P, Cossalter AM, Chou TC, Oswald IP (2017) Co-exposure to low doses of the food contaminants deoxynivalenol and nivalenol has a synergistic inflammatory effect on intestinal explants. Arch Toxicol 91:2677-2687. https ://doi.org/10.1007/s00204-016-1902-9

Alshannaq A, Yu JH (2017) Occurrence, toxicity, and analysis of major mycotoxins in food. Int J Environ Res Public Health 14:1-20. https://doi.org/10.3390/ijerph14060632

Ashley JN, Hobbs BC, Raistrick H (1937) Studies in the biochemistry of micro-organisms: the crystalline colouring matters of Fusarium culmorum (W. G. Smith) Sacc. and related forms. Biochem J 31:385-397

Bohets H, Annaert P, Mannens G et al (2001) Strategies for absorption screening in drug discovery and development. Curr Top Med Chem 1:367-383

Chou TC (2006) Theoretical basis, experimental design, and computerized simulation of synergism and antagonism in drug combination studies. Pharmacol Rev 58:621-681. https://doi.org/10.1124/ pr.58.3.10

Court MH (2010) Interindividual variability in hepatic drug glucuronidation: studies into the role of age, sex, enzyme inducers, and genetic polymorphism using the human liver bank as a model system. Drug Metab Rev 42:209-224. https://doi.org/10.3109/03602 530903209288

Court MH, Zhang X, Ding X, Yee KK, Hesse LM, Finel M (2012) Quantitative distribution of mRNAs encoding the 19 human UDP-glucuronosyltransferase enzymes in 26 adult and 3 fetal tissues. Xenobiotica 42:266-277. https://doi.org/10.3109/00498 254.2011.618954

Del Favero G, Woelflingseder L, Braun D et al (2018) Response of intestinal HT-29 cells to the trichothecene mycotoxin deoxynivalenol and its sulfated conjugates. Toxicol Lett 295:424-437. https ://doi.org/10.1016/j.toxlet.2018.07.007

Dong D, Ako R, Hu M, Wu B (2012) Understanding substrate selectivity of human UDP-glucuronosyltransferases through QSAR modeling and analysis of homologous enzymes. Xenobiotica 42:808-820. https://doi.org/10.3109/00498254.2012.663515

Dowd PF, Miller J, Greenhalgh R (1989) Toxicity and Interactions of some Fusarium graminearum metabolites to caterpillars. Mycologia 81:646-650. https://doi.org/10.2307/3760143

EFSA, Knutsen HK, Alexander J et al (2017a) Risks for animal health related to the presence of zearalenone and its modified forms in feed. EFSA Journal 15:e04851. https://doi.org/10.2903/j. efsa.2017.4851

EFSA, Knutsen HK, Alexander J et al (2017b) Risks to human and animal health related to the presence of deoxynivalenol and its acetylated and modified forms in food and feed. EFSA $\mathrm{J}$ 15:e04718. https://doi.org/10.2903/j.efsa.2017.4718

EFSA, Knutsen H-K, Alexander J et al (2018) Risks for animal health related to the presence of fumonisins, their modified forms and hidden forms in feed. EFSA J 16:e05242. https:// doi.org/10.2903/j.efsa.2018.5242

European Commission (2010) Directive 2010/63/EU of the European parliament and of the council of 22 September 2010 on the protection of animals used for scientific purposes. Off J Euro Union L 276(33): 1-47

Fraeyman S, Croubels S, Devreese M, Antonissen G (2017) Emerging Fusarium and alternaria mycotoxins: occurrence, Toxicity and Toxicokinetics. Toxins 9:228. https://doi.org/10.3390/toxin s9070228

Garreau de Loubresse N, Prokhorova I, Holtkamp W, Rodnina MV, Yusupova G, Yusupov M (2014) Structural basis for the inhibition of the eukaryotic ribosome. Nature 513:517-522. https:// doi.org/10.1038/nature13737

Ghebremeskel M, Langseth W (2001) The occurrence of culmorin and hydroxy-culmorins in cereals. Mycopathologia 152:103-108

Greenhalgh R, Meier RM, Blackwell BA, Miller JD, Taylor A, ApSimon JW (1984) Minor metabolites of Fusarium roseum (ATCC 28114). J Agric Food Chem 32:1261-1264. https://doi. org/10.1021/jf00126a013

Hanioka N, Obika N, Nishimura M et al (2006) Inducibility of UDP-glucuronosyltransferase 1 As by beta-naphthoflavone in HepG2 cells. Food Chem Toxicol 44:1251-1260. https://doi. org/10.1016/j.fct.2006.01.019

Hanioka N, Nonaka Y, Saito K et al (2012) Effect of aflatoxin B1 on UDP-glucuronosyltransferase mRNA expression in HepG2 cells. Chemosphere 89:526-529. https://doi.org/10.1016/j.chemospher e.2012.05.039

Hart SN, Li Y, Nakamoto K, Subileau EA, Steen D, Zhong XB (2010) A comparison of whole genome gene expression profiles of HepaRG cells and HepG2 cells to primary human hepatocytes and human liver tissues. Drug Metab Dispos 38:988-994. https://doi. org/10.1124/dmd.109.031831

Iordanov MS, Pribnow D, Magun JL et al (1997) Ribotoxic stress response: activation of the stress-activated protein kinase JNK1 by inhibitors of the peptidyl transferase reaction and by 
sequence-specific RNA damage to the alpha-sarcin/ricin loop in the 28S rRNA. Mol Cell Biol 17:3373-3381

Izukawa T, Nakajima M, Fujiwara R et al (2009) Quantitative analysis of UDP-glucuronosyltransferase (UGT) 1A and UGT2B expression levels in human livers. Drug Metab Dispos 37:1759-1768. https://doi.org/10.1124/dmd.109.027227

Kardon T, Coffey MJ, Banhegyi G et al (2000) Transcriptional induction of bilirubin UDP-glucuronosyltransrase by ethanol in rat liver. Alcohol 21:251-257

Kovalsky P, Kos G, Nahrer K et al (2016) Co-occurrence of regulated, masked and emerging mycotoxins and secondary metabolites in finished feed and maize-an extensive survey. Toxins 8:363. https ://doi.org/10.3390/toxins8120363

Laskin JD, Heck DE, Laskin DL (2002) The ribotoxic stress response as a potential mechanism for MAP kinase activation in xenobiotic toxicity. Toxicol Sci 69:289-291

Lauren DR, Ashley A, Blackwell B, Greenhalgh R, Miller J, Neish GA (1987) Trichothecenes produced by Fusarium crookwellense DAOM 193611. J Agri Food Chem 35:884-889. https://doi. org/10.1021/jf00078a008

Li YQ, Prentice DA, Howard ML, Mashford ML, Wilson JS, Desmond PV (2000) Alcohol up-regulates UDP-glucuronosyltransferase mRNA expression in rat liver and in primary rat hepatocyte culture. Life Sci 66:575-584. https://doi.org/10.1016/S0024 -3205(99)00630-X

Malachova A, Sulyok M, Beltran E, Berthiller F, Krska R (2014) Optimization and validation of a quantitative liquid chromatography-tandem mass spectrometric method covering 295 bacterial and fungal metabolites including all regulated mycotoxins in four model food matrices. J Chromatogr A 1362:145-156. https://doi.org/10.1016/j.chroma.2014.08.037

Marin S, Cano-Sancho G, Sanchis V, Ramos AJ (2018) The role of mycotoxins in the human exposome: application of mycotoxin biomarkers in exposome-health studies. Food Chem Toxicol 121:504-518. https://doi.org/10.1016/j.fct.2018.09.039

Maul R, Warth B, Kant JS et al (2012) Investigation of the hepatic glucuronidation pattern of the Fusarium mycotoxin deoxynivalenol in various species. Chem Res Toxicol 25:2715-2717. https ://doi.org/10.1021/tx300348x

Maul R, Warth B, Schebb NH, Krska R, Koch M, Sulyok M (2015) In vitro glucuronidation kinetics of deoxynivalenol by human and animal microsomes and recombinant human UGT enzymes. Arch Toxicol 89:949-960. https://doi.org/10.1007/s0020 4-014-1286-7

Miller J, MacKenzie S (2000) Secondary metabolites of Fusarium venenatum strains with deletions in the Tri5 gene encoding trichodiene synthetase. Mycologia 92:764-771. https://doi. org/10.2307/3761433

Nakamura A, Nakajima M, Yamanaka H, Fujiwara R, Yokoi T (2008) Expression of UGT1A and UGT2B mRNA in human normal tissues and various cell lines. Drug Metab Dispos 36:1461-1464. https://doi.org/10.1124/dmd.108.021428

Ohno S, Nakajin S (2009) Determination of mRNA expression of human UDP-glucuronosyltransferases and application for localization in various human tissues by real-time reverse transcriptasepolymerase chain reaction. Drug Metab Dispos 37:32-40. https:// doi.org/10.1124/dmd.108.023598

Pedersen PB, Miller JD (1999) The fungal metabolite culmorin and related compounds. Nat Toxins 7:305-309

Pestka JJ (2008) Mechanisms of deoxynivalenol-induced gene expression and apoptosis. Food Addit Contam Part A Chem Anal Control Expo Risk Assess 25:1128-1140

Pestka JJ (2010a) Deoxynivalenol-induced proinflammatory gene expression: mechanisms and pathological sequelae. Toxins 2:1300-1317. https://doi.org/10.3390/toxins2061300
Pestka JJ (2010b) Deoxynivalenol: mechanisms of action, human exposure, and toxicological relevance. Arch Toxicol 84:663-679. https ://doi.org/10.1007/s00204-010-0579-8

Pestka JJ, Zhou HR, Moon Y, Chung YJ (2004) Cellular and molecular mechanisms for immune modulation by deoxynivalenol and other trichothecenes: unraveling a paradox. Toxicol Lett 153:61-73. https://doi.org/10.1016/j.toxlet.2004.04.023

Pfeiffer E, Eschbach S, Metzler M (2007) Alternaria toxins: DNA strand-breaking activity in mammalian cellsin vitro. Mycotoxin Res 23:152-157. https://doi.org/10.1007/bf02951512

Poppenberger B, Berthiller F, Lucyshyn D et al (2003) Detoxification of the Fusarium mycotoxin deoxynivalenol by a UDP-glucosyltransferase from Arabidopsis thaliana. J Biol Chem 278:4790547914. https://doi.org/10.1074/jbc.M307552200

Prelusky D, Hamilton R, Trenholm H (1989) Application of the chick embryotoxicity bioassay for the evaluation of mycotoxin toxicity. Microbiol Aliments Nutr 7:57-65

Rotter RG, Trenholm HL, Prelusky DB, Hartin KE, Thompson BK, Miller JD (1992) A preliminary examination of potential interactions between deoxynivalenol (DON) and other selected Fusarium metabolites in growing pigs. Can J Anim Sci 72:107-116. https:// doi.org/10.4141/cjas92-012

Rowland A, Miners JO, Mackenzie PI (2013) The UDP-glucuronosyltransferases: their role in drug metabolism and detoxification. Int J Biochem Cell Biol 45:1121-1132. https://doi.org/10.1016/j. biocel.2013.02.019

Sarkanj B, Warth B, Uhlig S et al (2013) Urinary analysis reveals high deoxynivalenol exposure in pregnant women from Croatia. Food Chem Toxicol 62:231-237. https://doi.org/10.1016/j. fct.2013.08.043

Schmittgen TD, Livak KJ (2008) Analyzing real-time PCR data by the comparative C(T) method. Nat Protoc 3:1101-1108

Schwartz-Zimmermann HE, Hametner C, Nagl V et al (2017) Glucuronidation of deoxynivalenol (DON) by different animal species: identification of iso-DON glucuronides and iso-deepoxy-DON glucuronides as novel DON metabolites in pigs, rats, mice, and cows. Arch Toxicol 91:3857-3872. https://doi.org/10.1007/s0020 4-017-2012-z

Skehan P, Storeng R, Scudiero D et al (1990) New colorimetric cytotoxicity assay for anticancer-drug screening. J Natl Cancer Inst 82:1107-1112

Strassburg CP, Kneip S, Topp J et al (2000) Polymorphic gene regulation and interindividual variation of UDP-glucuronosyltransferase activity in human small intestine. J Biol Chem 275:36164-36171. https://doi.org/10.1074/jbc.M002180200

Streit E, Schwab C, Sulyok M, Naehrer K, Krska R, Schatzmayr G (2013) Multi-mycotoxin screening reveals the occurrence of 139 different secondary metabolites in feed and feed ingredients. Toxins 5:504-523. https://doi.org/10.3390/toxins5030504

Strongman DB, Miller JD, Calhoun L, Findlay JA, Whitney HJ (1987) The biochemical basis for interference competition among some lignicolous marine fungi. Bot Mar 30:21-26

Tourancheau A, Rouleau M, Guauque-Olarte S et al (2018) Quantitative profiling of the UGT transcriptome in human drug-metabolizing tissues. Pharmacogenomics J 18:251-261. https://doi. org/10.1038/tpj.2017.5

Tukey RH, Strassburg CP (2000) Human UDP-glucuronosyltransferases: metabolism, expression, and disease. Annu Rev Pharmacol Toxicol 40:581-616. https://doi.org/10.1146/annurev.pharm tox.40.1.581

Ueno Y (1977) Mode of action of trichothecenes. Ann Nutr Aliment 31:885-900

Uhlig S, Eriksen GS, Hofgaard IS, Krska R, Beltran E, Sulyok M (2013) Faces of a changing climate: semi-quantitative multi-mycotoxin analysis of grain grown in exceptional climatic conditions 
in Norway. Toxins 5:1682-1697. https://doi.org/10.3390/toxin s5101682

Vaclavikova M, Malachova A, Veprikova Z, Dzuman Z, Zachariasova M, Hajslova J (2013) 'Emerging' mycotoxins in cereals processing chains: changes of enniatins during beer and bread making. Food Chem 136:750-757. https://doi.org/10.1016/j.foodc hem.2012.08.031

Vejdovszky K, Hahn K, Braun D, Warth B, Marko D (2017) Synergistic estrogenic effects of Fusarium and Alternaria mycotoxins in vitro. Arch Toxicol 91:1447-1460. https://doi.org/10.1007/ s00204-016-1795-7

Vidal A, Claeys L, Mengelers M et al (2018) Humans significantly metabolize and excrete the mycotoxin deoxynivalenol and its modified form deoxynivalenol-3-glucoside within 24 hours. Sci Rep 8:5255. https://doi.org/10.1038/s41598-018-23526-9

Wang YZ, Miller JD (1988) Effects of Fusarium graminearum metabolites on wheat tissue in relation to fusarium head blight resistance. J Phytopathol 122:118-125. https://doi. org/10.1111/j.1439-0434.1988.tb00998.x

Warth B, Sulyok M, Berthiller F, Schuhmacher R, Krska R (2013a) New insights into the human metabolism of the Fusarium mycotoxins deoxynivalenol and zearalenone. Toxicol Lett 220:88-94. https://doi.org/10.1016/j.toxlet.2013.04.012

Warth B, Sulyok M, Krska R (2013b) LC-MS/MS-based multibiomarker approaches for the assessment of human exposure to mycotoxins. Anal Bioanal Chem 405:5687-5695. https://doi. org/10.1007/s00216-013-7011-1

Warth B, Del Favero G, Wiesenberger G et al (2016) Identification of a novel human deoxynivalenol metabolite enhancing proliferation of intestinal and urinary bladder cells. Sci Rep 6:33854. https:// doi.org/10.1038/srep33854
Weaver RJ, Betts C, Blomme EAG et al (2017) Test systems in drug discovery for hazard identification and risk assessment of human drug-induced liver injury. Expert Opin Drug Metab Toxicol 13:767-782. https://doi.org/10.1080/17425255.2017.1341489

Webb JL (1963) Enzyme and metabolic inhibitors. Academic Press, New York

Weber J, Vaclavikova M, Wiesenberger G et al (2018) Chemical synthesis of culmorin metabolites and their biologic role in culmorin and acetyl-culmorin treated wheat cells. Org Biomol Chem 16:2043-2048. https://doi.org/10.1039/c7ob02460f

Westerink WM, Schoonen WG (2007) Phase II enzyme levels in HepG2 cells and cryopreserved primary human hepatocytes and their induction in HepG2 cells. Toxicol In Vitro 21:1592-1602. https://doi.org/10.1016/j.tiv.2007.06.017

Wu B, Kulkarni K, Basu S, Zhang S, Hu M (2011) First-pass metabolism via UDP-glucuronosyltransferase: a barrier to oral bioavailability of phenolics. J Pharm Sci 100:3655-3681. https://doi. org/10.1002/jps.22568

Yokoyama Y, Sasaki Y, Terasaki N et al (2018) Comparison of Drug Metabolism and Its Related Hepatotoxic Effects in HepaRG, Cryopreserved Human Hepatocytes, and HepG2 Cell Cultures. Biol Pharm Bull 41:722-732. https://doi.org/10.1248/bpb.b17-00913

Publisher's Note Springer Nature remains neutral with regard to jurisdictional claims in published maps and institutional affiliations.

\section{Affiliations}

\section{Lydia Woelflingseder ${ }^{1} \cdot$ Benedikt Warth ${ }^{1} \cdot$ Immina Vierheilig $^{1} \cdot$ Heidi Schwartz-Zimmermann ${ }^{2} \cdot$ Christian Hametner $^{3}$. Veronika Nagl ${ }^{4}$. Barbara Novak ${ }^{4}$ Bojan Šarkanj ${ }^{5} \cdot$ Franz Berthiller $^{2} \cdot$ Gerhard Adam $^{6}$. Doris Marko ${ }^{1}$}

Lydia Woelflingseder

lydia.woelflingseder@univie.ac.at

Benedikt Warth

benedikt.warth@univie.ac.at

Immina Vierheilig

immina.vierheilig@gmail.com

Heidi Schwartz-Zimmermann

heidi.schwartz@boku.ac.at

Christian Hametner

christian.hametner@tuwien.ac.at

Veronika Nagl

veronika.nagl@biomin.net

Barbara Novak

barbara.novak@biomin.net

Bojan Šarkanj

bsarkanj@ptfos.hr

Franz Berthiller

franz.berthiller@boku.ac.at

Gerhard Adam

gerhard.adam@boku.ac.at
1 Department of Food Chemistry and Toxicology, Faculty of Chemistry, University of Vienna, Währingerstrasse 38, 1090 Vienna, Austria

2 Christian Doppler Laboratory for Mycotoxin Metabolism and Center for Analytical Chemistry, Department of Agrobiotechnology (IFA-Tulln), University of Natural Resources and Life Sciences, Vienna (BOKU), Konrad-Lorenz-Strasse 20, 3430 Tulln, Austria

3 Institute of Applied Synthetic Chemistry, Vienna University of Technology, Getreidemarkt 9/163, 1060 Vienna, Austria

4 BIOMIN Research Center, Technopark 1, 3430 Tulln, Austria

5 Department of Applied Chemistry and Ecology, Faculty of Food Technology, Josip Juraj Strossmayer University of Osijek, Franje Kuhača 20, 31000 Osijek, Croatia

6 Department of Applied Genetics and Cell Biology, University of Natural Resources and Life Sciences, Vienna (BOKU), Konrad-Lorenz-Strasse 24, 3430 Tulln, Austria 